\title{
Autoclave Synthesis Pd-Au and Pd-Pt Nanoparticles on Carbon Substrates
}

\author{
Roman V. Borisov, Oleg V. Belousov, \\ Anatoliy M. Zhizhaev and Ludmila I. Dorokhova* \\ Institute of Chemistry and Chemical Technology SB RAS \\ 50/24 Akademgorodok, Krasnoyarsk, 660036, Russia
}

Received 07.08.2015, received in revised form 29.08.2015, accepted 02.09.2015

\begin{abstract}
Palladium-carbon composite material was synthesized by hydrothermal reduction of tetraammin palladium chloride (II) in alkaline media at $170^{\circ} \mathrm{C}$. Morphology and size of the metal phase were investigated by scanning electron microscopy. Bimetallic particles Pd-Au and Pt-Pd on carbon substrates were prepared by interaction of palladium-carbon materials with muriatic solutions of gold(III) and platinum (IV) at $130^{\circ} \mathrm{C}$. It is found that varying contents of gold (III) and platinum (IV) in solution and the palladium metal in the initial composite may be prepared material with different ratios of metals. The phase of a palladium-gold is a substitutional solid solution was shown by X-ray diffraction.
\end{abstract}

Keywords: carbon materials, bimetallic nanoparticles, palladium, gold, platinum, autoclaves.

DOI: $10.17516 / 1998-2836-2015-8-3-377-385$.

(c) Siberian Federal University. All rights reserved

* Corresponding author E-mail address: roma_boris@list.ru 


\title{
Автоклавный синтез наноразмерных частиц Pd-Au и Pd-Pt на углеродных носителях
}

\author{
Р.В. Борисов, О.В. Белоусов, \\ А.М. Жижаев, Л.И. Дорохова \\ Институт химии и химической технологии СО РАН \\ Россия, 660036, Красноярск, Академгородок, 50/24
}

Гидротермальным восстановлением хлорида тетраамминпалладия(II) в щеелочных средах при $170{ }^{\circ} \mathrm{C}$ были синтезированы палладий-углеродные композиционные материаль. Сканирующей электронной микроскопией исследованы морфология и размеры металлических фаз. Взаимодействием палладий-углеродных материалов с солянокислыми растворами золота (III) и платины (IV) при $130{ }^{\circ} \mathrm{C}$ получены биметаллические частицы Pd-Au и Pd-Pt на углеродных носителях. Рентгенофазовым анализом показано, что фаза палладий-золото представляет собой твердый раствор замещения. Установлено, что варьированием содержания золота (III) и платины (IV) в растворе и металлического палладия в исходном композите можно получать материалы с различным соотнотением металлов.

Ключевые слова: углеродные материаль, биметаллические наночастищь, палладий, золото, платина, автоклавы.

\section{Введение}

Композиционные материалы, содержащие наноразмерные частицы благородных металлов, обладают рядом уникальных физико-химических свойств, отличных от объемных материалов, что позволяет применять их во многих областях - в гетерогенном катализе, топливных элементах и сенсорах [1]. В качестве матриц наряду с оксидными системами часто выступают углеродные материалы, которые обладают высокой удельной поверхностью, электрической проводимостью, превосходной химической и электрохимической стабильностью $[1,2]$. Наиболее часто в различных каталитических процессах используются монометаллические платина- или палладий-углеродные композиты [3, 4]. Однако добавление второго металла, по мнению авторов $[5,6]$, способствует изменению форм, состава, поверхностной морфологии, физико-химических свойств, включая каталитическую активность и химическую селективность по сравнению с монометаллическими аналогами. Поэтому исследование особенностей формирования биметаллических частиц представляется весьма актуальным.

Как было отмечено в [7], процессы с участием благородных металлов ввиду их химической инертности предпочтительно проводить при повышенных температурах, которые легко реализуются применением автоклавных технологий. В работах [7-13] детально проанализированы возможности и преимущества автоклавов для исследования гетерогенных процессов с участием благородных металлов: изучены механизмы варьирования структурными харак-

$$
-378-
$$


теристиками палладия [8] и родия [9], исследованы процессы формирования твердых растворов и структур по типу «ядро-оболочка» $[10,11]$, подобраны условия обогащения платиновых концентратов при повышенных температурах $[12,13]$.

В предыдущей работе [14] были рассмотрены вопросы формирования наноразмерных фаз палладия и платины автоклавным восстановлением соответствующих аммиачных комплексов в щелочных средах. Цель настоящей работы - изучение процессов формирования наноразмерных биметаллических фаз палладий-золото и палладий-платина на углеродных носителях в гидротермальных условиях.

\section{Экспериментальная часть}

Эксперименты проводили в титановых автоклавах с фторопластовыми вкладышами $\left(30 \mathrm{~cm}^{3}\right)$ и кварцевых автоклавах $\left(40 \mathrm{~cm}^{3}\right)$ при температурах до $170{ }^{\circ} \mathrm{C}$ по методике, подробно описанной в предыдущих работах $[15,16]$. Все используемые реактивы имели квалификацию не ниже «х.ч.».

Концентрации элементов в растворах определяли методами атомно-абсорбционной спектроскопии AAnalyst-400 (Perkin Elmer, США) и масс-спектрометрии с индуктивно связанной плазмой ICP-MS 7500a (Agilent, США).

Микроскопические исследования проводили на сканирующих электронных микроскопах TM-3000 и S5500 (Hitachi, Япония), укомплектованных рентгеноспектральным анализатором. Удельную поверхность и объем пор определяли газовой адсорбцией азота с помощью анализатора ASAP-2420 (Micromeritics, США) при 77 К. Расчет удельной поверхности образцов осуществляли с использованием модели ВЕТ. Рентгенофазовый анализ проводили на дифрактометре X'Pert Pro MPD (PANalytical, Нидерланды).

Текстурные характеристики используемых в работе углеродных материалов (УМ) даны в табл. 1. УМГ - гранулы черного цвета диаметром около 2 мм, УМ - материал на основе углеродных нанотрубок, представляет собой одномерные наномасштабные нитевидные образования длиной более 2 мкм с наружными диаметрами от 15 до 40 нм в виде сыпучего порошка черного цвета.

\section{Результаты и обсуждение}

Ранее [16] нами было показано, что при температуре $170{ }^{\circ} \mathrm{C}$ в среде $0,05 \mathrm{M}$ гидроксида калия в автоклавах водные растворы хлорид тетраамминпалладия(II) восстанавливаются до наноразмерных порошков палладия:

$$
3\left[\mathrm{Pd}\left(\mathrm{NH}_{3}\right)_{4}\right] \mathrm{Cl}_{2}+6 \mathrm{KOH} \rightarrow 3 \mathrm{Pd}+\mathrm{N}_{2}+10 \mathrm{NH}_{3}+6 \mathrm{H}_{2} \mathrm{O}+6 \mathrm{KCl}
$$

Таблица 1. Характеристики исходных УМ

\begin{tabular}{|c|c|c|c|}
\hline Образец & $\begin{array}{c}\text { Удельная } \\
\text { поверхность, } \mathbf{M}^{2} / \Gamma\end{array}$ & Объем пор, см$^{3} / \Gamma$ & $\begin{array}{c}\text { Средний } \\
\text { диаметр пор, нм }\end{array}$ \\
\hline УМГ & 372 & 0,80 & 7,5 \\
\hline УМ & 152 & 0,27 & 6,9 \\
\hline
\end{tabular}


Данным способом наночастицы палладия были нанесены на УМ и УМГ. Характеристики полученных образцов приведены в табл. 2. На образце Pd/УМГ значительное сокращение поверхности и объема пор объясняется равномерным восстановлением металлической фазы по поверхности гранул углеродного материала [13], что подтверждается микроскопическими исследованиями.

В случае материала Pd/УМ-1 электронно-микроскопически обнаружены металлические частицы палладия размером как 20-40 нм, так и более крупные - 70-120 нм, которые сформировались среди нитевидных образований углерода (рис. 1a) и состоят из более мелких фрагментов. Увеличение содержания палладия и времени автоклавного восстановления со 120 (Pd/УМ-1) до 240 минут (Рd/УМ-2) приводит к увеличению размеров частиц металла (80-130 нм) и более равномерному обволакиванию углеродных нитей (рис. 1б). Металлическая фаза достаточно крепко соединена с углеродным скелетом: после обработки материала при $25^{\circ} \mathrm{C}$ в $1 \mathrm{M}$ соляной кислоте ультразвуком (ванна «Сапфир») частицы палладия остались на нитях углерода и существенных изменений в морфологии не произошло.

При взаимодействии материала УМ с солянокислым раствором $\mathrm{HAuCl}_{4}\left(\mathrm{C}_{\mathrm{Au}}=\right.$ 1,00 ммоль/л) в автоклавных условиях при $110{ }^{\circ} \mathrm{C}$ в течение 4 ч концентрация золота в растворе согласно данным атомно-адсорбционного анализа уменьшилась до 0,55 ммоль/л. Этот процесс может быть обусловлен восстановлением золота на углеродном носителе. Действительно, методом сканирующей электронной микроскопии с рентгеноспектральным анализом на поверхности углерода обнаружены металлические частицы золота; наряду с частицами неправильной формы (50-200 нм) встречаются симметричные структуры

Таблица 2. Характеристики композиционных материалов $\mathrm{Pd} / \mathrm{YM}$

\begin{tabular}{|c|c|c|c|c|}
\hline Образец & \% Pd (масс.) & $\mathrm{S}$ пов-ти, $\mathrm{M}^{2} / \Gamma$ & Объем пор, $\mathrm{cm}^{3} / \Gamma$ & $\begin{array}{c}\text { Средний диаметр } \\
\text { пор, нм }\end{array}$ \\
\hline $\mathrm{Pd} / \mathrm{YM}-1$ & 5,8 & 146 & 0,26 & 6,9 \\
\hline $\mathrm{Pd} / \mathrm{YM}-2$ & 8,3 & 144 & 0,26 & 6,9 \\
\hline $\mathrm{Pd} / \mathrm{УМГ}$ & 0,9 & 353 & 0,68 & 7,0 \\
\hline
\end{tabular}

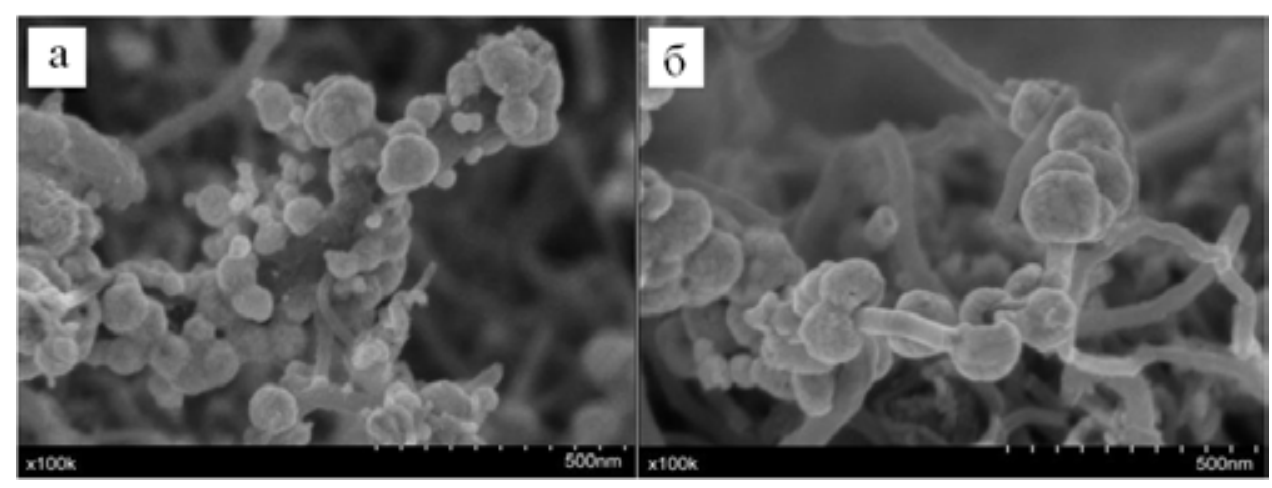

Рис. 1. Фрагмент микрофотографии материала: а - Pd/УМ-1; б - Pd/УМ-2

$$
-380-
$$


с размерами более 1 мкм. Фрагмент микрофотографии с изображением нескольких частиц золота приведен на рис. 2.

Ранее [10] нами показано, что при температурах $110-130{ }^{\circ} \mathrm{C}$ нанокристаллический палладий восстанавливает золото(III) из солянокислых растворов:

$$
2 \mathrm{HAuCl}_{4}+3 \mathrm{Pd}+4 \mathrm{HCl} \rightarrow 2 \mathrm{Au}+3 \mathrm{H}_{2} \mathrm{PdCl}_{4}
$$

В результате взаимодействия получены биметаллические частицы Pd-Au, состоящие из ядра палладия, окруженного фазой твердого раствора $\mathrm{Pd}-\mathrm{Au}$, состав которой можно целенаправленно изменять, меняя мольное соотношение $\mathrm{Pd} / \mathrm{Au}$, температуру и время процесса [10]. Наряду с восстановлением золота(III) (2) происходит растворение (3) металлического палладия вследствие его окисления кислородом [8], как содержащимся в газовой фазе автоклава, так и хемосорбированным на поверхности образца. Поэтому, чтобы минимизировать растворение палладия за счет кислорода воздуха, эксперименты проводили в атмосфере аргона.

$$
2 \mathrm{Pd}+\mathrm{O}_{2}+8 \mathrm{HCl} \rightarrow 2 \mathrm{H}_{2} \mathrm{PdCl}_{4}+2 \mathrm{H}_{2} \mathrm{O} .
$$

Взаимодействие $\mathrm{Pd} / \mathrm{УM}-2$ с раствором $\mathrm{HAuCl}_{4}\left(\mathrm{C}_{\mathrm{Au}}=1,0\right.$ ммоль/л) при $110{ }^{\circ} \mathrm{C}$ в течение 4 ч приводит к количественному восстановлению золота. При этом в раствор перешло 30 \% металлического палладия: согласно стехиометрии 20 \% за счет протекания процесса цементации (2) и остальное, вероятно, за счет растворения палладия (3) вследствие наличия на его поверхности хемосорбированного кислорода. Сведением материального баланса был рассчитан состав полученного композита Pd-Au/УМ-2: 2,0 \% масс. Аu, 5,8 \% масс. Рd. Электронно-микроскопические исследования показали, что вокруг нитевидных образований углеродного материала формируются полые сферы (120 - 150 нм), которые согласно рентгеноспектральному анализу состоят из палладия (0) и золота (0) (рис. 3). При этом соотношение металлов варьируется в разных точках от 2:1 до 4:1, что согласуется с данными материального баланса и позволяет сделать вывод о равномерном распределении металлов по углеродному носителю. Рентгенофазовым анализом наряду с рефлексами углеродного носителя зафиксировано наличие двух фаз: металлического палладия и твердого раствора $\mathrm{Pd}-\mathrm{Au}$, обогащенного золотом. На рентгенограммах наблюда-

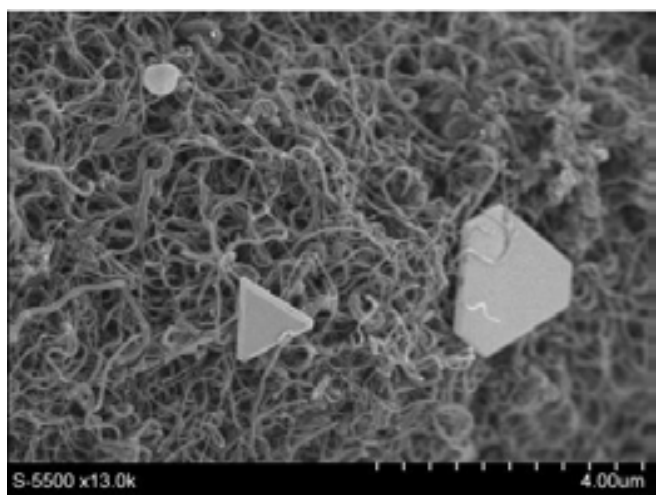

Рис. 2. Фрагмент микрофотографии продукта взаимодействия УМ с раствором $\mathrm{H}_{2} \mathrm{AuCl}_{4}$ в автоклавных условиях $\left(110^{\circ} \mathrm{C}, 240\right.$ мин) 


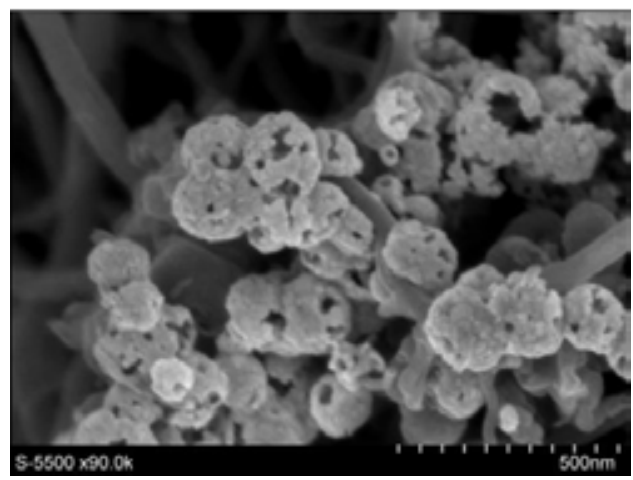

Рис. 3. Фрагмент микрофотографии композита $\mathrm{Pd}-\mathrm{Au} / \mathrm{YM}-2$ (соотношение $\mathrm{Au}: \mathrm{Pd}$ согласно рентгеноспектральному анализу 1:3)

ются уширения дифракционных линий, которые могут быть обусловлены неоднородностью химического состава и дисперсностью металлических фаз. Отдельные частицы золота (0) на микрофотографиях не обнаружены, что говорит о восстановлении золота (III) за счет протекания процесса цементации (2). При увеличении концентрации золота (III) в исходном растворе до 4 ммоль/л (стехиометрическое соотношение для процесса (2)) при $110{ }^{\circ} \mathrm{C}$ в течение 4 ч происходит количественное его восстановление, которое сопровождается растворением палладия (0). Химический анализ показал, что в композиционном материале остается до 25 \% палладия. Данный факт можно объяснить изоляцией палладия (0) от раствора. Такая ситуация рассмотрена в работе [10]. Дальнейшее уменьшение концентрации золота (III), по всей видимости, происходит за счет его восстановления углеродным материалом, как описано выше. Действительно, в этом случае согласно данным электронной микроскопии на углеродном носителе обнаружены отдельно лежащие крупные металлические частицы (1-3 мкм), в составе которых преобладает золото.

Взаимодействие материала $\mathrm{Pd} / \mathrm{УМГ} \mathrm{при} 130{ }^{\circ} \mathrm{C}$ в течение 4 ч с раствором $\mathrm{HAuCl}_{4}\left(\mathrm{C}_{\mathrm{Au}}=\right.$ 0,25 ммоль/л) приводит к количественному восстановлению золота и растворению половины металлического палладия. Состав композита $\mathrm{Pd}-\mathrm{Au} / \mathrm{YM \Gamma} \mathrm{(0,2} \mathrm{\%} \mathrm{мас.} \mathrm{Au} \mathrm{и} \mathrm{0,5} \mathrm{\%} \mathrm{мас.} \mathrm{Pd.),} \mathrm{pac-}$ считанный сведением материального баланса, хорошо согласуется с соотношением золота и палладия, полученным из рентгеноспектральных данных. Размер частиц металлической фазы составляет 80-120 нм.

Использование металлического палладия (0), нанесенного на углеродный материал, в качестве цементатора возможно для восстановления не только золота (III), но и для растворов платины (II) и (IV). В работе [17] изучены механизмы взаимодействия палладиевой черни с солянокислыми растворами $\mathrm{H}_{2} \mathrm{PtCl}_{4}$ и $\mathrm{H}_{2} \mathrm{PtCl}_{6}$ при температуре $130{ }^{\circ} \mathrm{C}$ и установлено, что продуктом являются твердые растворы палладий-платина. Суммарно процесс может быть описан уравнением

$$
\mathrm{H}_{2} \mathrm{PtCl}_{6}+2 \mathrm{Pd}+2 \mathrm{HCl} \rightarrow \mathrm{Pt}+2 \mathrm{H}_{2} \mathrm{PdCl}_{4} .
$$

Взаимодействие УМ с раствором $\mathrm{Pt}(\mathrm{IV})\left(\mathrm{C}_{\mathrm{Pt}}=1,7\right.$ ммоль/л) при $130{ }^{\circ} \mathrm{C}$ в течение 4 ч приводит к незначительному снижению концентрации платины до 1,6 ммоль/л, что, ве- 


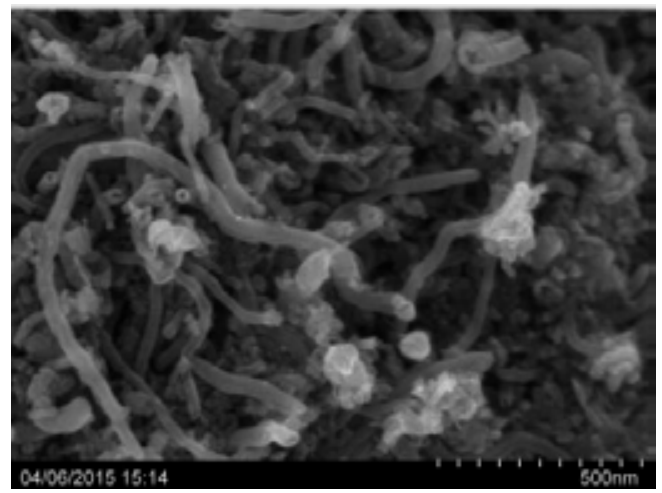

Рис. 4. Фрагмент микрофотографии композита Pd-Pt/УМ-1

роятно, связано с процессами сорбции. При контакте материала $\mathrm{Pd} / \mathrm{YM}-1$ с растворами $\mathrm{H}_{2} \mathrm{PtCl}_{6}$ различных концентраций $\left(\mathrm{C}_{\mathrm{Pt}}=0,1 \div 1,7\right.$ ммоль/л) при $130{ }^{\circ} \mathrm{C}$ в течение $1 \div 4$ часов без удаления кислорода воздуха происходит растворение до 80 \% металлического палладия, преимущественно за счет протекания процесса (3). Глубина восстановления платины (IV) согласно данным атомно-адсорбционного анализа достигает от $18 \%$ при времени взаимодействия 1 ч до $25 \%$ при контакте в течение 4 ч. Полученные материалы Pd-Pt/ УМ-1 содержат от 1,5 до $1,2 \%$ мас. палладия и от 0,2 до $0,6 \%$ мас. платины. На рис. 4 показан фрагмент микрофотографии композиционного материала Pd-Pt/УM-1 (1,2 \% мас. $\mathrm{Pd}, 0,6$ \% мас. $\mathrm{Pt}$ ): частицы металлической фазы размером 80 - 150 нм распределены среди углеродных нитей. В отличие от системы $\mathrm{Pd}-\mathrm{Au} / \mathrm{YM}-2$ равномерно распределенные сферы, пронизанные волокнами углерода, отсутствуют, что связано с высокой долей растворения палладия.

Таким образом, в результате взаимодействия палладий-углеродных материалов с солянокислыми растворами золота (III) и платины (IV) при повышенных температурах образуются биметаллические частицы Pd-Au и Pd-Pt. Варьируя содержание металлов в твердой фазе и растворе, продолжительность процесса и температуру, можно формировать на углеродных носителях металлические фазы различного состава.

Исследование выполнено при финансовой поддержке РФФИ в рамках научного проекта № 14-03-31075 мол_а.

\section{Список литературы}

1. Wu B., Kuang Y., Zhang X., Chen J. Noble metal nanoparticles/carbon nanotubes nanohybrids: synthesis and applications //Nano Today. 2011. Vol. 6. No. 1. P. 75-90.

2. Чесноков Н.В., Кузнецов Б.Н., Микова Н.М. Углеродные и композиционные материалы из природных графитов // Журнал Сибирского федерального университета. Химия. 2013. Т 6. №1. C.11-22. [Chesnokov N.V., Kuznetsov B.N., Mikova N.M. Synthesis and Properties of Carbonaceous and Composite Materials from Natural Graphite // Journal of Siberian Federal University. Chemistry. 2013. 6(1), 11-22. (In Russ.)] 
3. Cheng N. et al. An ambient aqueous synthesis for highly dispersed and active $\mathrm{Pd} / \mathrm{C}$ catalyst for formic acid electro-oxidation//Journal of Power Sources. 2010. Vol. 195. No. 21. P. 7246-7249.

4. Симакова, И. Л., Морозов, А. А., Тарабанько, В. Е., Черняк М.Ю. Каталитическое гидрирование 5-бутоксиметилфурфурола на палладиевых катализаторах // Журнал Сибирского федерального университета. Химия. 2014. T. 7. №4. C. 537-546. [Simakova I.L., Morozov A.A., Tarabanko V.E., Chernyak M.Yu. 5-butoxymethylfurfural Catalytic Hydrogenation over Palladium Catalysts // Journal of Siberian Federal University. Chemistry. 2014. 7(4), 537-546. (In Russ.)]

5. Kung C. C. et al. Three dimensional graphene foam supported platinum-ruthenium bimetallic nanocatalysts for direct methanol and direct ethanol fuel cell applications //Journal of Power Sources. 2014. Vol. 256. P. 329-335.

6. Alayoglu S., Nilekar A. U., Mavrikakis M., Eichhorn B. Ru-Pt core-shell nanoparticles for preferential oxidation of carbon monoxide in hydrogen // Nature materials. 2008. Vol. 7. No. 4. P. 333338.

7. Formation of Nanomaterials Based on Non-Ferrous and Noble Metals in Autoclaves / O.V. Belousov, A.V. Sirotina, N.V. Belousova, E.V. Fesik, R.V. Borisov., G.D. Malchikov //Journal of Siberian Federal University. Engineering \& Technologies. 2014. №2. C.138-145.

8. Белоусов О.В., Дорохова Л.И., Соловьев Л.А., Жарков С.М. Изменение размеров частиц высокодисперсной палладиевой черни в солянокислых растворах при повышенных температурах // Журнал физической химии. 2007. T.81. №8. C.1479-1482. [Belousov, O. V., Dorokhova, L. I., Solov'ev, L. A., Zharkov, S. M.. Change in the particle size of highly dispersed palladium black in hydrochloric acid solutions at elevated temperatures.// Russian Journal of Physical Chemistry A. 2007. 81(8), 1303-1306].

9. Коваленко Н.Л., Белоусов О.В., Дорохова Л.И., Жарков С.М. Исследование укрупнения Pd- и Rh-черней и механизма образования твердых растворов в реакциях цементации // Журнал неорганической химии. 1995. T. 40. № 4. C. 678-682. [Kovalenko, N. L., Belousov, O. V., Dorokhova, L. I., Zharkov, S. M. A study of the increase in sized of particles of palladium and rhodium blacks and the mechanisms of the solid solution formations in cementing reactions // Russian journal of inorganic chemistry. 1995. 40(4), 657-661].

10. Formation of Bimetallic $\mathrm{Au}-\mathrm{Pd}$ and $\mathrm{Au}-\mathrm{Pt}$ Nanoparticles under Hydrothermal Conditions and Microwave Irradiation / O.V. Belousov, L.A. Solovyov, A.M. Zhyzhaev, Y.L. Mikhlin, N.V. Belousova, A.V. Sirotina, S.M. Zharkov // Langmuir. 2011. Vol. 27. Issue 18. P. 11697-11703.

11. Белоусов О.В., Белоусова Н.В. Взаимодействие родия с хлорокомплексами палладия при повышенных температурах // Журнал Сибирского федерального университета. Техника и технологии. 2015. Т.8. №4. С. 507-513. [Belousov O. V., Belousova N. V. Interaction of Rhodium with Chloro-Complexes of Palladium at Elevated Temperatures //Journal of Siberian Federal University. Engineering \& Technologies. 2015. 8(4), 507-513 (In Russ.)].

12. Белоусов О.В., Белоусова Н.В., Рюмин А.И., Борисов Р.В. Поведение концентратов платиновых металлов в автоклавных условиях // Журнал прикладной химии. 2015. Т. 88. Вып. 1. C. 35-39. [Belousov O. V., Belousova N. V., Ryumin A. I., Borisov R. V. Behavior of platinum metal concentrates under autoclave conditions / Russian Journal of Applied Chemistry. 2015 88(1), 31-34]. 
13. Белоусов О.В., Белоусова Н.В., Рюмин А.И., Борисов Р.В. Обогащение платинопалладиевого концентрата в гидротермальных условиях // Журнал прикладной химии. 2015. T. 88. Вып. 6. C. 984-987. [Belousov O. V., Belousova N. V., Ryumin A. I., Borisov R. V. Refining of platinum-palladium concentrate under hydrothermal conditions.// Russian Journal of Applied Chemistry. 2015 88(6), 1078-1081].

14. Борисов Р.В., Белоусов О.В. Формирование нанокристаллических фаз палладия и платины на углеродных носителях в автоклавных условиях // Журнал Сибирского федерального университета. Химия. 2014. Т7. №3. C.331-339. [Borisov R. V., Belousov O. V. Formation Nanocrystalline Phases of Palladium and Platinum on a Carbon Support in Autoclave Conditions // Journal of Siberian Federal University. Chemistry. 2014. 7(3), 331-339 (In Russ.)].

15. Коваленко Н.Л., Шеина И.В., Белоусов О.В. Гидролиз и редокспревращения $\left[\mathrm{Rh}\left(\mathrm{NH}_{3}\right)_{5} \mathrm{Cl}\right] \mathrm{Cl}_{2}$ в щелочных растворах при повышенной температуре и под действием микроволнового излучения // Журнал прикладной химии. 1995. Т.68. №3. С.377-380. [Kovalenko N.L., Sheina I.V., Belousov O.V. Hydrolysis and redox transformations of $\left[\mathrm{Rh}\left(\mathrm{NH}_{3}\right)_{5} \mathrm{Cl}\right] \mathrm{Cl}_{2}$ in alkaline solutions at elevated temperature under microwave radiation / // Russ. J. Appl. Chem. 1995. 68(3), 323-326].

16. Борисов Р.В., Белоусов О.В. Получение наноразмерных частиц палладия на углеродных носителях в автоклавных условиях // Вестник Кемеровского государственного университета. 2014. Т 3. Вып. 59. №3. C.174-177. [Borisov R. V., Belousov O. V. Preparation of palladium nanoparticles on carbon substrates in autoclave conditions// The bulletin of Kuz-STU. 2014. 59(3), 174-177 (In Russ.)].

17. Коваленко Н.Л., Белоусов О.В., Дорохова Л.И. Восстановление палладиевой чернью хлорокомплексов платины при температуре $130^{\circ} \mathrm{C} / /$ Журнал неорганической химии. 2002. Т. 47. №7. C. 1074-1077. [Kovalenko N.L., Belousov O.V., Dorokhova L.I. Reduction of platinum chloro complexes by palladium black at $130{ }^{\circ} \mathrm{C} / /$ Russian journal of inorganic chemistry. 2002. 47(7), 967970.] 